\title{
The use of annual physical examinations among the elderly in rural China: a cross-sectional study
}

\author{
Xi Sun ${ }^{1 \dagger}$, Yingchun Chen ${ }^{1 \dagger}$, Xuetao Tong ${ }^{1}$, Zhanchun Feng ${ }^{1 *}$, Li Wei $^{2}$, Donghua Zhou ${ }^{1}$, Miaomiao Tian ${ }^{3}$, \\ Benyan LV ${ }^{1}$ and Da Feng ${ }^{1}$
}

\begin{abstract}
Background: Periodic physical examination is considered helpful in preventing illness and promoting health among the elderly. Limited information is available about the use of annual physical examinations among the elderly in rural areas, however. This research explores the distribution characteristics of annual physical examination use and its determinants among people aged 60 or over in rural China.

Methods: A cross-sectional study was undertaken to estimate distribution characteristics of annual physical examination use and to collect data of sociodemographic characteristics, health knowledge level, and health communication channels. Participants were 1128 people aged 60 or over, randomly selected from four different provinces in the East, Mid-East, Mid-West, and West China. Logistic regression determined the predictors of annual physical examination use.
\end{abstract}

Results: Participants were predominantly aged 60-79 (44.1\%) and 70-79 (42.0\%). A total of 716 (63.5\%) participants underwent annual physical examinations. Those who reported acquiring health knowledge via bulletin boards and village doctors had a higher probability of using annual physical examinations ( $O R=3.15$ and 1.53$)$. The probability for civil servants/retired having annual physical examinations was 2.16 times higher than for farmers. Those who had an average level of health knowledge had a higher probability of using annual physical examinations than those at the below-average level (odds ratio: 2.07).

Conclusion: The government and public health institutions should assist farmers to acquire the habit of having annual physical examinations. Traditional channels, such as bulletin boards, should be used to deliver health information. Village doctors should be supported in delivering health information to the elderly in rural areas.

Keywords: Rural, Annual physical examination, Health services use, Elderly, Chinese

\section{Background}

Periodic physical examination is considered an important and effective measure in the prevention of illness and promotion of health [1,2]. Moreover, it provides an opportunity for health status evaluation, preventive health consultation, and physician-patient relationship promotion [3]. In some situations, such as screening for cancer, periodic physical examination is very important $[4,5]$.

\footnotetext{
* Correspondence: zcfeng@hust.edu.cn

${ }^{\dagger}$ Equal contributors

${ }^{1}$ Medicine and Health Management School, Tongji Medical College, Huazhong University of Science and Technology, 13 Hangkong Rd., Wuhan, Hubei 430030, PRC

Full list of author information is available at the end of the article
}

Good health is essential for the elderly to maintain an independent lifestyle and make a contribution to their families and communities [6]. However, the elderly often suffer from diseases, especially chronic diseases such as hypertension, diabetes, and dyslipidemia, and these diseases are a heavy economic burden for the elderly [7]. Therefore, it is necessary and appropriate for the elderly to have periodic physical examinations [8].

Population aging in China is already happening; the proportion of those aged 60 or over increased by $3.82 \%$, from $9.67 \%$ to $13.49 \%$, between 1990 and 2010 [9]. Only $14.6 \%$ of rural Chinese adults aged 65 or above had an annual physical examination in 2008 [10]. In China, county hospitals, town hospitals, and village clinics compose the three-tier rural health service network. They

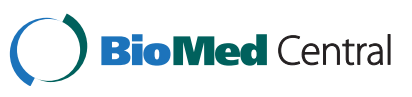


are the principal providers of health care services to rural residents to maintain their health. Under the new health care reform scheme, annual physical examinations were to be provided free of charge to adults aged 65 or over in rural China by town hospitals from 2009. In some regions, the age requirement was lowered to 60 [11,12]. In the past 3 years, from 2009 to 2012, the takeup of annual physical examinations among people aged 60 or over increased rapidly, especially among people aged 65 or over $[13,14]$.

Many studies have explored factors that affect the use of preventive health services, such as educational level, income, and self-rated living status [15]. The factor of economic barriers, in particular, has been mentioned frequently. People who have high income and private insurance are able to access preventive health services more easily [16-18]. Some studies [1,19-22] have also suggested that men are less likely to use preventive health services than women. Green and Pope (1999) mention that there are two views to explain why women use preventive health services more frequently. Some believe it is because women have higher morbidity rates, while others argue that it is because they are more sensitive to symptoms and care more about their health [19].

Age, income, and chronic diseases are also influencing factors in using community health services by elderly Chinese [23]. This means that those who are older, have a higher income, and who suffer with chronic diseases are more likely to use community health services. In other studies, elderly people who live alone, so-called empty nesters, use fewer community health services [24]. Health communication based on community can help the elderly to establish healthy behavior patterns and living habits, which can be effective in preventing and controlling the occurrence of various chronic diseases [25].

For the past 3 years, free annual physical examinations have been provided to Chinese adults aged 65 or over (60 or over in some regions) [11,12]. To our knowledge, there are almost no studies about the use of annual physical examination among adults aged 60 or above in rural China. As the predictors for usage of annual physical examinations among this group are unknown, this study examined the level and predictors for their availing of annual physical examinations. Specifically, the research questions are (1) To what extent do adults aged 60 or over in rural China avail of the annual physical examination? (2) What are the potentially modifiable factors associated with availing of this service?

\section{Methods}

\section{Study population}

A cross-sectional survey study using stratified multistage sampling was conducted in July and August 2011.
The sampling procedure involved five levels: province/ municipality, county, township, village, and respondent. First, all the 31 provinces/municipalities in China were divided into four groups according to the Human Development Index [26], and one province/municipality was selected at random from each group. Zhejiang Province (in East China), Henan Province (in Mid-East China), Chongqing Municipality (in Mid-West China), and Qinghai Province (in West China) were chosen as the study sites (Figure 1). Second, each of the four selected study sites' counties were divided into three groups according to their economic development level, and one county was selected from each group as the representative county $(4 \times 3=12$ counties selected). Third, the same procedure was repeated at the township level to select the representative townships $(4 \times 3 \times 3=$ 36 townships selected). Fourth, all the villages in each selected township were grouped into three categories according to their distance from the center of the town, and one village was selected randomly from each category $(4 \times 3 \times 3 \times 3=108$ villages selected). Fifth, 11 or 12 rural adults aged 60 or over were selected at random in each selected village from the candidates listed in health records. A total of 1128 adults aged 60 or over were thus sampled from the 108 villages and completed the survey.

Face-to-face interviews were conducted by interviewers with each participant, and the study purpose was clearly explained to them. Students from the School of Medicine and Health Management of Tongji Medical College and staff members of local health care institutions were recruited and trained as interviewers. Survey items and response choices were read to participants who had difficulty reading because of illiteracy or poor vision.

This study was approved by the Ethics Committee of Tongji Medical College, Huazhong University of Science and Technology. Informed consent was obtained from all participants in the study.

\section{Questionnaire}

All participants completed the Use of Annual Physical Examination Survey (Additional file 1). The questionnaire was delivered in simplified Chinese and contained closed-ended questions (true/false/don't know format). The questionnaire consisted of three parts: 1) basic information; 2) health knowledge; and 3) means of acquiring health knowledge. The basic information comprised demographic and socioeconomic information. The demographic information collected comprised gender, age, and number of household members. The socioeconomic information collected comprised educational level, occupation, annual disposable household income, type of health insurance, and time required to reach township hospitals. Health knowledge items were 


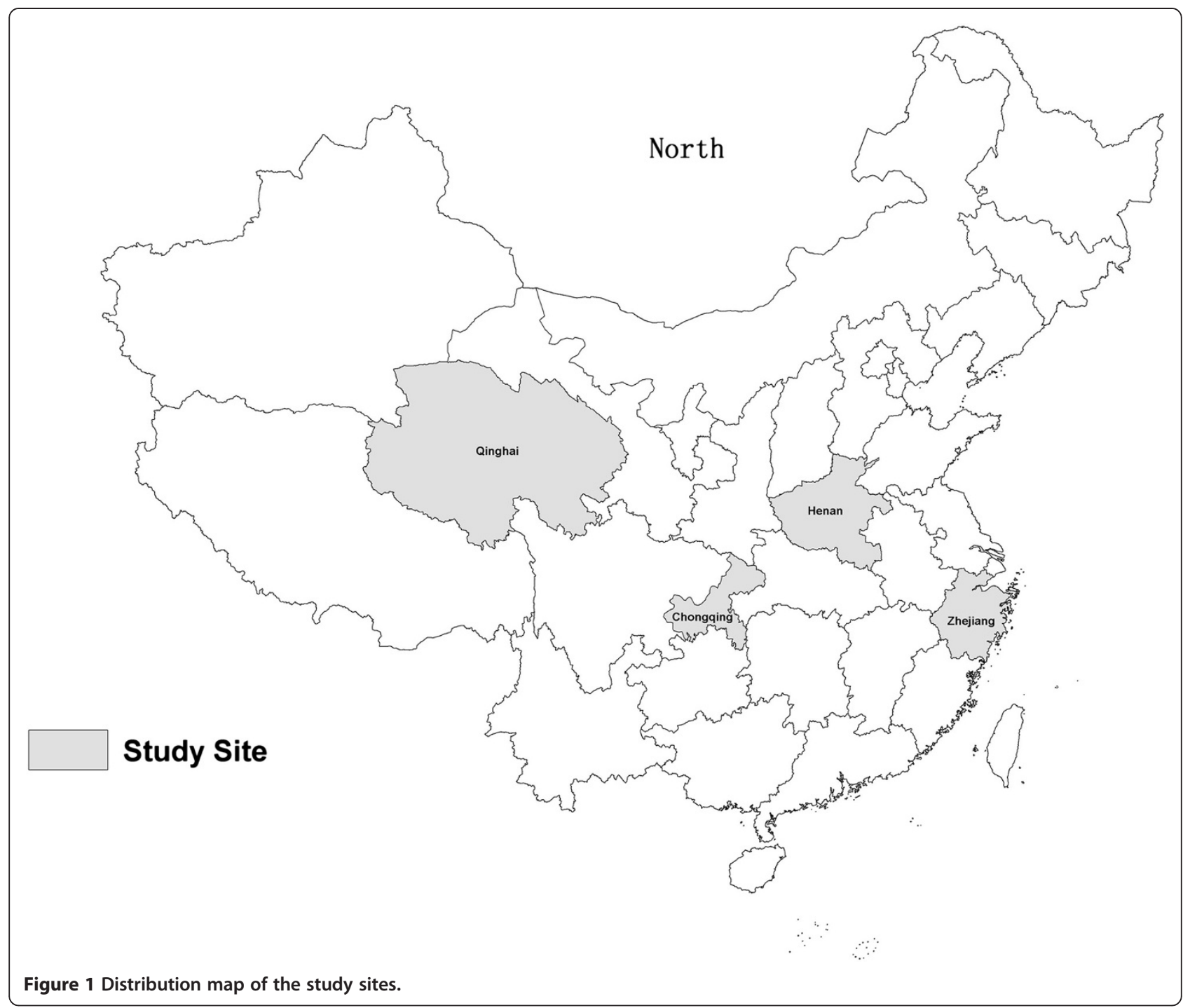

developed by referring to the 2008 Chinese Citizens' Health Literacy Survey [10] and health brochures delivered to residents in rural China. On the basis of these materials, we identified 10 items that were easily understandable by the elderly for our questionnaire. The total number of correct answers was calculated as the overall health knowledge score. No points would be awarded for incorrect or missing answers or the answer "don't know." Participants who obtained a score at/or above eight points were considered to have an above-average level of health knowledge. Those who obtained a score of five points or less were considered to have a belowaverage level of health knowledge. Those who obtained a score of six or seven were considered to have an average level of health knowledge. Health communication channels comprised TV or radio broadcasts, the Internet, bulletin boards, friends or family members, and doctors.

\section{Statistical methods}

Basic sociodemographic characteristics of the participants were summarized using descriptive statistics. Prior to conducting logistic regression analysis to identify the predictors of annual physical examination use, Chi-square and Fisher's exact tests (whenever appropriate) were used to explore differences in value of the covariates between user and non-user groups of annual physical examinations to select potential predictors for the regression analysis. Logistic regression was then applied to examine the potential predictors of annual physical examination use. The dependent variable was whether (1) or not (0) each participant had annual physical examination. Independent variables included: occupation, number of household members, health knowledge level, means of acquiring health knowledge.

In this research, all data were entered twice into the EpiData 3.1, while data entry screens were used to rectify 
incorrect entries (e.g., logic and input errors). Statistical analysis was conducted using SPSS statistics 12 . Statistical significance level was set at 0.05 .

\section{Results}

\section{Sociodemographic characteristics of participants}

Slightly more than half (53.9\%) of the participants were male, and most of them were farmers (78.6\%). Participants were predominantly aged $60-79(44.1 \%)$ or $70-79$ $(42.0 \%)$. More than $85 \%$ of them were at or below elementary educational level. Other demographic and socioeconomic characteristics are presented in Table 1.

\section{Annual physical examination use}

Among the total 1128 participants, 63.5\% (716) were users of annual physical examinations. Results of the bivariate analysis (Table 2) indicated significant differences between users and nonusers of annual physical examinations in some of the variables. The users tended to be civil servants or retired, belong to households of two or fewer members, have average or above-average levels of health knowledge, and acquire their health knowledge via TV or radio broadcasts, the Internet, bulletin boards, doctors, and family members and/or friends. No significant difference was reported between users and nonusers in gender, age, education level, type of health insurance, time required to reach township hospital, or annual disposable household income.

\section{Predictors of annual physical examination use among rural Chinese elderly}

Because the bivariate effects of the predictors on the dependent variable were probably confounded by other factors, multivariate logistic regression analysis was further used to examine the predicting effect of each potential predictor identified in the bivariate analysis to adjust for the effects of other confounding variables. Four predictors-occupation, health knowledge level, and two health communication channels (doctors and bulletin boards)-were retained in the final logistic regression model to predict annual physical examination use among rural Chinese adults aged 60 or over (Table 3). Among all the significant predictors, the factor of health communication channel (bulletin boards) had the highest odds ratio. Those who reported acquiring their health knowledge via bulletin boards and village doctors had a higher probability of having annual physical examinations (odds ratio: 3.15 and 1.53). The probability for civil servants/retired was 2.16 times higher than for farmers. It is interesting that those who had an average level of health knowledge had a higher probability of using annual physical examinations than those at the below-average level (odds ratio: 2.07), but those who had an above-average level of health knowledge had almost
Table 1 Sociodemographic characteristics of the elderly aged 60 or over in rural China

\begin{tabular}{|c|c|c|}
\hline Characteristics & $\begin{array}{l}\text { Frequency } \\
(n=1128)\end{array}$ & Percentage (\%) \\
\hline \multicolumn{3}{|l|}{ Gender } \\
\hline Male & 608 & 53.9 \\
\hline Female & 520 & 46.1 \\
\hline \multicolumn{3}{|l|}{ Age } \\
\hline $60-69$ & 497 & 44.1 \\
\hline $70-79$ & 474 & 42.0 \\
\hline 80 or over & 157 & 13.9 \\
\hline \multicolumn{3}{|l|}{ Education level } \\
\hline Less than 6 years elementary study & 610 & 54.1 \\
\hline Elementary & 361 & 32.0 \\
\hline Middle school and above & 157 & 13.9 \\
\hline \multicolumn{3}{|l|}{ Occupation $^{*}$} \\
\hline Farmer & 887 & 78.6 \\
\hline Self-employed or Migrant worker & 103 & 9.1 \\
\hline Civil servant or retired & 138 & 12.2 \\
\hline \multicolumn{3}{|l|}{ Type of health insurance } \\
\hline New cooperative medical system & 1104 & 97.9 \\
\hline Non-new cooperative medical system & 24 & 2.1 \\
\hline \multicolumn{3}{|l|}{ Number of household members } \\
\hline 1 & 97 & 8.6 \\
\hline 2 & 278 & 24.6 \\
\hline $3-4$ & 388 & 34.4 \\
\hline 5 or above & 365 & 32.4 \\
\hline \multicolumn{3}{|c|}{ Time required to reach township hospitals } \\
\hline Less than 10 min & 858 & 76.1 \\
\hline $10 \mathrm{~min}$ to $19 \mathrm{~min}$ & 187 & 16.6 \\
\hline 20 min and above & 83 & 7.4 \\
\hline \multicolumn{3}{|l|}{ Annul disposable household income } \\
\hline Less than CNY 10,000 & 441 & 39.1 \\
\hline CNY 10,000 to CNY 19,999 & 265 & 23.5 \\
\hline CNY 20,000 and above & 422 & 37.4 \\
\hline
\end{tabular}

*Self-employed means people who run a private small-scale business by themselves, such as food-shop owners, repair-shop owners and rice-noodles sellers. Migrant worker means the rural people who go into the cities to do an off-farm work but go back to their villages in harvest seasons and in Chinese traditional festivals.

Civil servant means people who are employed by the government, public sectors or enterprise held by the government. Retired means people who retired from these institutions.

the same probability as those with a below-average level (odds ratio: 0.95).

\section{Discussion}

In this study, we have not found any evidence for the impact of gender, type of health insurance, or annual disposable household income on the use of annual 
Table 2 Bivariate Correlates* of annual physical examination use among rural Chinese elderly aged 60 or over

\begin{tabular}{|c|c|c|c|c|c|c|}
\hline \multirow[t]{3}{*}{ Potential predictor } & \multirow{2}{*}{\multicolumn{2}{|c|}{$\begin{array}{c}\text { User of annual physical examination } \\
\qquad(\mathrm{n}=716)\end{array}$}} & \multirow{2}{*}{\multicolumn{2}{|c|}{$\begin{array}{c}\text { Nonusers of annual } \\
\text { physical examination }(n=412)\end{array}$}} & \multirow[t]{3}{*}{$x^{2}$} & \multirow[t]{3}{*}{ p-value } \\
\hline & & & & & & \\
\hline & $\mathrm{N}$ & $\%$ & $\mathbf{N}$ & $\%$ & & \\
\hline \multicolumn{7}{|l|}{ Occupation } \\
\hline Farmer & 541 & 75.6 & 346 & 84 & 13.495 & 0.001 \\
\hline Self-employed or & 69 & 9.6 & 34 & 8.3 & & \\
\hline \multicolumn{7}{|l|}{ migrant worker } \\
\hline Civil servant or retired & 106 & 14.8 & 32 & 7.8 & & \\
\hline \multicolumn{7}{|c|}{ Number of household members } \\
\hline 1 & 73 & 10.2 & 24 & 5.8 & 11.754 & 0.008 \\
\hline 2 & 189 & 26.4 & 89 & 21.6 & & \\
\hline $3-4$ & 237 & 33.1 & 151 & 36.7 & & \\
\hline 5 and above & 217 & 30.3 & 148 & 35.9 & & \\
\hline \multicolumn{7}{|l|}{ Health knowledge level } \\
\hline Below average & 403 & 56.3 & 286 & 69.4 & 19.793 & $<.001$ \\
\hline Average & 228 & 31.8 & 86 & 20.9 & & \\
\hline Above average & 85 & 11.9 & 40 & 9.7 & & \\
\hline \multicolumn{7}{|c|}{ Health communication channel } \\
\hline \multicolumn{7}{|l|}{ TV or radio broadcast } \\
\hline No & 276 & 38.5 & 240 & 58.3 & 40.914 & $<.001$ \\
\hline Yes & 440 & 61.5 & 172 & 41.7 & & \\
\hline \multicolumn{7}{|l|}{ Internet } \\
\hline No & 633 & 88.4 & 393 & 95.4 & 15.493 & $<.001$ \\
\hline Yes & 83 & 11.6 & 19 & 4.6 & & \\
\hline \multicolumn{7}{|l|}{ Bulletin board } \\
\hline No & 327 & 45.7 & 317 & 76.9 & 104.395 & $<.001$ \\
\hline Yes & 389 & 54.3 & 95 & 23.1 & & \\
\hline \multicolumn{7}{|l|}{ Doctor } \\
\hline No & 144 & 20.1 & 166 & 40.3 & 53.435 & $<.001$ \\
\hline Yes & 572 & 79.9 & 246 & 59.7 & & \\
\hline \multicolumn{7}{|c|}{ Family member and friend } \\
\hline No & 270 & 37.7 & 217 & 52.7 & 23.857 & $<.001$ \\
\hline Yes & 446 & 62.3 & 195 & 47.3 & & \\
\hline
\end{tabular}

*Only significant correlates are presented.

physical examinations by adults aged 60 or over in rural China. This result differed from those of some previous investigations $[19,27,28]$, which examined factors predicting the use of other preventive or medical services. It is generally believed that females suffer from more diseases and are more sensitive to their health status. Moreover, the effects of economic barriers to preventive or medical services are common but were not identified as predictors in this study. This could be due to the wide coverage of the New Cooperative Medical System (NCMS) [29], which increased the financing standard from CNY30 to CNY300 per person and the personal payment standard from CNY10 to CNY60 per person
[29,30]. To some extent, the NCMS has reduced the burden of disease, especially for adults in rural areas. In addition, annual physical examinations have been provided free of charge to the elderly in rural areas since 2009.

According to previous studies, higher occupational levels may contribute to an understanding of healthy behaviors [31]. This study showed that, compared with civil servants/retired, farmers were less likely to have annual physical examinations. There are two possible reasons. First, civil servants (either on the job or retired) are used to having annual physical examinations. A free medical insurance system (since the 1950s) and a 


\begin{tabular}{|c|c|c|c|c|c|c|}
\hline \multirow[t]{2}{*}{ Predictor } & \multirow[t]{2}{*}{ Reference category } & \multirow[t]{2}{*}{ B } & \multirow[t]{2}{*}{ OR } & \multicolumn{2}{|c|}{ 95\% C.I. } & \multirow[t]{2}{*}{ p-value } \\
\hline & & & & Lower & Upper & \\
\hline Occupation & Farmer & & & & & \\
\hline Self-employed or & & 0.312 & 1.366 & 0.806 & 2.315 & 0.247 \\
\hline \multicolumn{7}{|l|}{ migrant worker } \\
\hline Civil servant or & & 0.772 & 2.163 & 1.251 & 3.741 & 0.006 \\
\hline \multicolumn{7}{|l|}{ retired } \\
\hline Health knowledge level & Below average & & & & & \\
\hline Average & & 0.729 & 2.073 & 1.427 & 3.011 & $<.001$ \\
\hline Above average & & -0.054 & 0.948 & 0.565 & 1.591 & 0.840 \\
\hline \multicolumn{7}{|c|}{ Health communication channel } \\
\hline Doctor & No & 0.426 & 1.532 & 1.080 & 2.171 & 0.017 \\
\hline Bulletin board & No & 1.147 & 3.149 & 2.219 & 4.467 & $<.001$ \\
\hline
\end{tabular}

medical insurance system for urban employees (since the 1980s) have been in place for many years, providing health insurance for civil servants employed by the government or in the public sector. Civil servants only have to pay a small part of the cost to receive an annual physical examination. By contrast, free annual physical examination services were unavailable to farmers until the healthcare reform of 2008, so they are not in the habit of using such services. Second, civil servants' work units remind them when their annual physical examination is due and sometimes even arrange it for them. For civil servants who do not avail of the service, their units will remind them repeatedly. Farmers, by contrast, do not have scheduled physical examinations because they are busy farming. Although public health institutions have an obligation to remind them to have their annual physical examination, only one reminder is given.

According to the Knowledge, Attitude, Belief, and Practice (KABP) Model, health knowledge is the foundation of healthy attitudes, beliefs, and practices. People who have more health knowledge are more likely to behave healthily. In this study, we found that people who had an average level of health knowledge were more likely to avail of annual physical examinations, but having a level of health knowledge either below or above the average did not increase the likelihood of having an annual physical examination. It is reasonable to expect that those with a below-average level of health knowledge would be less likely to have an annual physical examination, but it is surprising that those with an above-average level were no more likely to have an annual physical examination. This may be explained by the fact that the free annual physical examination provided by the government only covers basic items. Those who have an above-average level of health knowledge may not believe in the value of such a basic examination.
They may prefer to self-assess their health status on the basis of their health knowledge or to pay for a more detailed examination.

Health communication is essential to promoting and protecting the health of the public and is now being regarded as a vital core component of public health [32]. In general, the main objective of health communication is to influence individuals and communities. In rural Chinese regions, health communication channels include the interpersonal (e.g., doctors and family members or friends), mass media (e.g., TV or radio broadcasting), and the community-specific (e.g., local bulletin boards $[25,33])$. In this study, we found that the most popular and effective health communication channels are bulletin boards and village doctors.

Bulletin boards are very popular in rural China. They are set up and managed by village committees, and they have public credibility because they represent the public and government. All the important information about a village, such as election dates, natural disaster warnings, and physical examination times, will be published on its bulletin boards. Generally, the bulletin boards are set up beside the village committee's workplace or in the gateway of the village so that they are convenient for villagers. It is believed to be an effective means of communicating health information because health communication channels that can reach a large proportion of the target population many times within a given period are more effective than those that do not $[34,35]$.

Interpersonal communication is very important. This includes communication between the healthcare provider and the patient but also between the patient and others, especially other patients. Communication between healthcare providers and patients may affect the receipt of health services [36,37]. There are also a number of known barriers, such as language [27,28], gender 
[38], and disability [39], that can interfere with healthcare communication between providers and patients. Trust in physicians is also associated with the use of preventive health services; it is more important than trust in medical research and health information sources [40]. In particular, Chinese village doctors are indigenous and trusted by local villagers. They usually exhort villagers to avail of the annual physical examination. Communication between villagers is also very important [27,41], however, and health information from other patients is more easily trusted. That it was not shown to be a predictor in this study may be because of interference in provider-patient communication.

Mass media health campaigns have been an important strategy for health promotion and disease prevention. They are often more cost-effective than interpersonal channels because a very large audience can be reached after the initial investment in message production $[42,43]$. The public can receive various kinds of health knowledge from mass media because a large volume of health information is available to them. Adults in rural areas often watch or listen to health programs on TV or radio, the most popular mass media in rural China. In this study, however, the acquisition of information this way was not found to be a significant predictor of use of annual physical examination. This may be because there is almost no health information about the annual physical examination available via the mass media and because health programs are not tailored for the elderly in rural areas.

One of the limitations to this study is that some predictors found by other researchers (e.g., survey participants' health status) were not included. Another research limitation is the use of closed-ended questions in the health knowledge test, which may have allowed participants to guess the correct answer. In addition, we assumed that the demographic and socioeconomic factors selected for this study, together with the selected health communication channels, are likely to be the main factors of influence for annual physical examination use among rural adults aged 60 or over in China, so other possible predictors were not considered.

\section{Conclusion}

This study highlighted the relationship between health communication channels and annual physical examination use among adults aged 60 or more in rural China, as well as the predictors of the usage patterns of annual physical examination. The results emphasized the importance of two health communication channels, namely village doctors and bulletin boards, which are the most popular and trusted channels in rural China. The results also revealed the disparity among the adults of different occupations and levels of health knowledge.
On the basis of our findings and discussions, three recommendations can be given. First, the government and public health institutions should give special attention to farmers and help them to acquire the habit of having an annual physical examination. Second, we should pay more attention to the use of traditional channels of communication, such as bulletin boards, to deliver health information because they are visible, accessible, and cost-effective. Third, village doctors should be supported in delivering health information to the elderly in rural areas because they are trusted figures.

\section{Additional file}

Additional file 1: Questionnaire for annual physical examination use among the elderly in rural China. Part A: Socio-demographic

Characteristics. Part B: Health knowledge. Part C: Health communication channels. Part D: Use of annual physical examination.

\section{Abbreviation}

NCMS: New cooperative medical system.

\section{Competing interests}

The authors declare that they have no competing interests.

\section{Authors' contributions}

Study concept and design: XS, YC and XT. Data collection: LW, DZ, MT, BL and DF. Statistical analysis: XS, YC and XT. Analysis and interpretation of data: $S X, Y C$ and $X T$. Draft of the manuscript: XS. Critical revision of the manuscript for important intellectual content: XS, YC, ZF, and XT. Administrative, technical, and material support: ZF and XS. Study supervision: ZF. All authors read and approved the final manuscript.

\section{Acknowledgements}

This research is supported by the National Natural Science Foundation of China (70973042). The authors would like to thank the National Natural Science Foundation of China for the funding of this research. The authors also would like to thank WONG Ho Ting and Mr. John Green for the help in language edit.

\section{Author details}

${ }^{1}$ Medicine and Health Management School, Tongji Medical College, Huazhong University of Science and Technology, 13 Hangkong Rd., Wuhan, Hubei 430030, PRC. ${ }^{2}$ Union Hospital, Tongji Medical College, Huazhong University of Science and Technology, 1227 Jiefang Rd, Wuhan, Hubei 430022, PRC. ${ }^{3}$ Institute of Medical Information, Center for Health Policy and Management, Chinese Academy of Medical Sciences, 3 Yabao Rd, Chaoyang, Beijing 100020, PRC

Received: 9 March 2013 Accepted: 7 January 2014 Published: 14 January 2014

\section{References}

1. Culica D, Rohrer J, Ward M, Hilsenrath P, Pomrehn P: Medical checkups: who does not get them? Am J Public Health 2002, 92(1):88-91.

2. Lai DW, Kalyniak S: Use of annual physical examinations by aging Chinese Canadians. J Aging Health 2005, 17(5):573-591.

3. Prochazka AV, Lundahl K, Pearson W, Oboler SK, Anderson RJ: Support of evidence-based guidelines for the annual physical examination: a survey of primary care providers. Arch Intern Med 2005, 165(12):1347.

4. Fenton JJ, Cai Y, Weiss NS, Elmore JG, Pardee RE, Reid RJ, Baldwin LM: Delivery of cancer screening: how important is the preventive health examination? Arch Intern Med 2007, 167(6):580-585.

5. Sox CH, Dietrich AJ, Tosteson TD, Winchell CW, Labaree CE: Periodic health examinations and the provision of cancer prevention services. Arch Fam Med 1997, 6(3):223-230. 
6. WHO: International plan of action on ageing: report on implementation report by the secretariat; 2012

7. Wen-jing M: Study on disease burden of common chronic diseases among community middle-elderly-people, Master. Southeast University, Social Security; 2007

8. Si-qing L: Importance of regular physical examination for early prevention and treatment of disease in middle aged and elderly people. ChinJ Convalescent Med 2009, 18(5):429-430.

9. World population prospects: the 2010 revision. [http://esa.un.org/unpd/wpp/ Excel-Data/population.htm]

10. Notice from the Ministry of Health: basic knowledge and skills in health literacy of Chinese residents, Volume 2012. [http://www.gov.cn/gzdt/2008-02/05/ content_884068.htm]

11. People aged 60 and over in Gaoxin community participated in the annual physical examination for free. [http://www.ccms.gov.cn/gxajb01/37996.htm]

12. People aged 60 and over in Tianjin participated in the periodic physical examination for free; 2011 [http://www.022net.com/2013/1-2/ 442557122278100.html]

13. Yong-lan W, Rong LU, Wei Z, Jin-jie X, Xian L, Zhong P: Analysis on community-based management for elder population in Chengdu. Chin J Public Health Manag 2011, 4:414-415.

14. People aged 65 and over in Zhang Zhuang participated in the annual physical examination for free, Volume 2012; 2010 [http://ydbd.yandu.gov.cn/ view_content.asp?article_bianhao=20101122039]

15. Chun $\mathrm{H}, \mathrm{Kim} \mathrm{H}$ : Socioeconomic inequalities in preventive services among the elderly: results from medical checkup, cancer check, and BP check. J Prev Med Public Health 2007, 40(5):404-410.

16. Faulkner LA, Schauffler $\mathrm{HH}$ : The effect of health insurance coverage on the appropriate use of recommended clinical preventive services. Am J Prev Med 1997, 13(6):453-458.

17. Nelson KM, Chapko MK, Reiber G, Boyko EJ: The association between health insurance coverage and diabetes care; data from the 2000 behavioral risk factor surveillance system. Health Serv Res 2005, 40(2):361-372.

18. Saver BG, Peterfreund N: Insurance, income, and access to ambulatory care in King County Washington. Am J Public Health 1993, 83(11):1583-1588.

19. Green CA, Pope CR: Gender, psychosocial factors and the use of medical services: a longitudinal analysis. Soc Sci Med 1999, 48(10):1363-1372.

20. Koopmans GT, Lamers LM: Gender and health care utilization: the role of mental distress and help-seeking propensity. Soc Sci Med 2007, 64(6):1216-1230

21. Redondo-Sendino A, Guallar-Castillon P, Banegas JR, Rodriguez-Artalejo F: Gender differences in the utilization of health-care services among the older adult population of Spain. Bmc Public Health 2006, 6:155.

22. Xiong GL, losif AM, Bermudes RA, McCarron RM, Hales RE: Preventive medical services use among community mental health patients with severe mental illness:the influence of gender and insurance coverage. Prim Care Companion J Clin Psychiatry 2010, 12(5):441-445.

23. Xiao-man Z, Hong-xia W, Hui-min Ll: Analysis of utilization and influencing factors for community health service of the elderly population in Xuzhou. Chin J Pract Nurs 2013, 29(16):5-7.

24. Li-juan L, Wei-min R, Yue W: The influence of "empty nest" on health and equality of health service utilization among the elderly in Shanghai. Chin Health Ser Manag 2011, 28(9):672-673.

25. Qi-qi W: Health communication: help the elderly to establish health habits, Master. University of Science and Technology of China, Communication; 2008.

26. Zhang Z, Pan J, Cui S, Zhao Y, Zhong N: Preterm births in countries with a very high human development index, Volume 381. Geneva: World Health Organization; 2013:1355.

27. Matejic B, Vukovic D, Pekmezovic T, Kesic V, Markovic M: Determinants of preventive health behavior in relation to cervical cancer screening among the female population of Belgrade. Health Educ Res 2011, 26(2):201-211.

28. Wu B: Dental service utilization among urban and rural older adults in China - a brief communication. J Public Health Dent 2007, 67(3):185-188.

29. Work progress in 2011 and important arrangements in 2012 of new cooperative medical system. [http://www.moh.gov.cn/mohbgt/s3582/201202/ 54209.shtml]

30. Notice on government work arrangements in 2012 about new cooperative medical system. [http://www.mof.gov.cn/zhengwuxinxi/bulinggonggao/ tongzhitonggao/201205/t20120528_654516.html]
31. Rosenstock IM: Why people use health services. Milbank Q 2005, 83(4). Online-only.

32. Bernhardt JM: Communication at the core of effective public health Am J Public Health 2004, 94(12):2051-2053.

33. Lee JS: Channels of health communications used among Korean and Asian Indian older adults. Soc Work Health Care 2010, 49(2):165-175.

34. Andreasen AR: Public health communication: evidence for behavior change. Soc Mark Q 2002, 8(3):38-41.

35. Shimp TA: Advertising, promotion: and supplemental aspects of integrated marketing communications. Ohio, EUA: Thomson; 2003.

36. Flach SD, McCoy KD, Vaughn TE, Ward MM, Bootsmiller BJ, Doebbeling BN: Does patient-centered care improve provision of preventive services? J Gen Intern Med 2004, 19(10):1019-1026.

37. Lasser KE, Kelly B, Maier J, Murillo J, Hoover S, Isenberg K, Osber D, Pilkauskas N, Willis BC, Hersey J: Discussions about preventive services: a qualitative study. BMC Fam Pract 2008, 9:49.

38. Bernzweig J, Takayama Jl, Phibbs C, Lewis C, Pantell RH: Gender differences in physician-patient communication. Evidence from pediatric visits. Arch Pediatr Adolesc Med 1997, 151(6):586-591.

39. Smith DL: Disparities in patient-physician communication for persons with a disability from the 2006 Medical Expenditure Panel Survey (MEPS). Disabil Health J 2009, 2(4):206-215.

40. Musa D, Schulz R, Harris R, Silverman M, Thomas SB: Trust in the health care system and the use of preventive health services by older black and white adults. Am J Public Health 2009, 99(7):1293-1299.

41. Kakai $H$, Maskarinec G, Shumay DM, Tatsumura Y, Tasaki K: Ethnic differences in choices of health information by cancer patients using complementary and alternative medicine: an exploratory study with correspondence analysis. Soc Sci Med 2003, 56(4):851-862.

42. Hornik RC: Development communication: information, agriculture, and nutrition in the Third World. Lanham, USA: University Press of America; 1993.

43. Snyder LB: Health communication campaigns and their impact on behavior. J Nutr Educ Behav 2007, 39(2 Suppl):S32-S40.

doi:10.1186/1472-6963-14-16

Cite this article as: Sun et al:: The use of annual physical examinations among the elderly in rural China: a cross-sectional study. BMC Health Services Research 2014 14:16.

\section{Submit your next manuscript to BioMed Central and take full advantage of:}

- Convenient online submission

- Thorough peer review

- No space constraints or color figure charges

- Immediate publication on acceptance

- Inclusion in PubMed, CAS, Scopus and Google Scholar

- Research which is freely available for redistribution 